LAPORAN KASUS

\title{
Penatalaksanaan Anestesi pada Koreksi Atresia Esophagus dan Atresia Esofagus
}

\author{
Anesthesia Management Patient with Esophageal Atresia/Tracheoesophageal \\ Fistula
}

Fadli Armi Lubis $\bowtie *$, Hasanul Arifin*

* Bagian Anestesi dan Terapi intensif Fakultas Kedokteran Universitas Sumatera Utara/ RSU Haji Adam Malik , Medan

$\triangle$ Korespondensi/correspondence: fadliarmilubis@yahoo.co.id

\begin{abstract}
Background: Esophageal atresia is a congenital medical condition (birth defect) which affects the digestive tract. Congenital anatomical defect is caused by an abnormal embryological development of esophageal fistula forming tracheoesofageal. Surgical repair is the definitive treatment for EA and TEF. Due to fistula, the airway tract is altered and the anesthesiologist should face a unique challenge on its management
\end{abstract}

Case : A baby boy, admitted to hospital with main complaint vomitus after breastfed. Physical findings shown as crackles on breath sound. Intubation using awake technique. During operation, hemodynamic was stable, maintanance with sevoflurane MAC 1\%, fentanyl $4 \mu \mathrm{g} / \mathrm{hr}$, and rocuronium 0,5 $\mathrm{mg} / \mathrm{hr}$. When desaturation occured, we stop the operation, we check the tube in place, gave adequate ventilation, after a while the saturation rises and then the operation procedure continued. However, anastomose of esophagus could not be done because the distance between the defect was too far. Duration of the operation was about 4 hours. Awake intubation technique was used. Hemodynamic was stable during surgery, and found TEF type C. After surgery patient was taken cared in NICU and 3 days later the patient died.

Summary: Good anesthetic management using "awake intubation" and good ventilation is a chosen technique in this case. The operation lasted 4 hours with stable hemodynamics. However, because the operation did not successfully correct the defect, then the postoperative outcome were futile.

Keyword: Anesthesia management, congenital anomaly, tracheoesophageal fistula

\begin{abstract}
ABSTRAK
Pendahuluan : Atresia esofagus adalah suatu kondisi medis bawaan ( cacat lahir) yang mempengaruhi saluran pencernaan . Cacat bawaan anatomi disebabkan oleh perkembangan embrio abnormal fistula esofagus membentuk tracheoesofageal. Bedah perbaikan adalah pengobatan definitif untuk EA dan TEF . Karena fistula, saluran napas diubah dan ahli anestesi harus menghadapi tantangan unik pada manajemen
\end{abstract}


Kasus : Seorang bayi laki-laki, masuk rumah sakit dengan keluhan utama muntah setelah disusui. Temuan fisik ditemukan ronki basah kasar pada suara napas. Intubasi menggunakan teknik intubasi sadar. Selama operasi, hemodinamik stabil, maintanance dengan sevofluran MAC $1 \%$, fentanil $4 \mathrm{mg} /$ jam, dan rocuronium 0,5 $\mathrm{mg} / \mathrm{jam}$. Durasi operasi adalah sekitar 4 jam. Hemodinamik stabil selama operasi, dan menemukan TEF tipe C. Ketika desaturasi terjadi, kami menghentikan sejenak operasi, kami memeriksa posisi ETTat, memberikan ventilasi yang cukup, setelah beberapa saat saturasi naik dan kemudian operasi dilanjutkan . Meski demikan anastomose esofagus gagal dilakukan karena jarak antara cacat itu terlalu jauh. Setelah pasien operasi diambil dirawat di NICU dan 3 hari kemudian pasien meninggal.

Ringkasan: Manajemen anestesi baik menggunakan " intubasi sadar " dan ventilasi yang baik adalah teknik yang dipilih dalam kasus ini. Operasi berlangsung 4 jam dengan hemodinamik stabil. Namun, karena operasi tidak berhasil memperbaiki cacat tersebut , maka hasil pasca operasi kurang baik.

Kata Kunci: Manajemen anestesi, kelainan kongenital , fistula trakeoesofageal

\section{PENDAHULUAN}

Fistula trakheoesofagus merupakan kelainan kongenital yang terjadi sekitar 1 dalam 4000 kelahiran hidup, lebih dari $85 \%$ disertai dengan atresia oesofagus. Cacat bawaan dari sudut anatomis disebabkan oleh perkembangan embrio yang abnormal oleh karena adanya fistula esofagus membentuk tracheoesofageal fistel. Perbaikan dari segi pembedahan adalah pengobatan definitif untuk kelainan ini. Pembedahan umumnya dilakukan dalam waktu 24 hingga 72 jam pada neonatus sehat. Keterlambatan dalam melakukan koreksi atresia oesophagus dapat meningkatkan resiko aspirasi.Berdasarkan hasil penelitian sekitar $70 \%$ kebanyakan bayi yang mengalaminya, memiliki paling tidak satu abnormalitas lain. Hampir 20 - $25 \%$ disertai dengan penyakit jantung bawaan, meliputi ventricular septal defect, patent ductus arteriosus, tetralogy of fallot, atrial septal defect, atrioventricular canal, coartasio aorta dan arcus aorta.

Kecenderungan abnormalitas penyerta lebih banyak pada kasus atresia oesofagus tunggal dan lebih sedikit pada kasus fistula trakheoesophagus tunggal. Kelainan penyerta yang paling banyak terjadi pada fistula trakheoesophagus dan atresia esophagus dapat diingat dengan singkatan VACTERL ${ }^{1,2}$ yaitu Vertebra, Anorektal, Cardiac, Tracheal, Esophageal, Renal, dan Limb

\section{KASUS}

Seorang bayi laki-laki, 14 hari, berat badan 2200 gr, dibawa ke rumah sakit dengan keluhan utama muntah setelah diberikan ASI (air susu ibu). Pemeriksaan fisik dijumpai adanya ronki pada suara pernapasan. Analisa gas 
darah laboratorium pH: 7,33 / pCO2: 42,8 / pO2: 63,5 / Bic: 22,4 / Tot.CO2: 23,7 / BE: -3,3 / SpO2: 92, 8\%. Laboratorium lain dalam batas normal. Temuan radiologi: Atresia esofagus proksimal dengan fistel trakeoesofageal dan dijumpai aspirasi pneumonia. Ekokardiografi: struktur jantung dan fungsi normal. Pasien direncanakan untuk elektif torakotomi. Pasien di premedikasi dengan $0,1 \mathrm{mg}$ sulfas atropin. Intubasi menggunakan teknik "awake intubation". Selama operasi hemodinamik stabil, pemeliharaan dengan sevofluran MAC 1\%, fentanyl 4 $\mu \mathrm{g} / \mathrm{jam}$, dan rocuronium $0,5 \mathrm{mg} / \mathrm{jam}$. Bila desaturasi, operasi dihentikan sementara dan diberikan ventilasi. Operasi berlangsung 4 jam dan pasien ditransfer ke NICU untuk perawatan lanjutan.

\section{PEMBAHASAN}

Beberapa kesulitan ditemukan selama manajemen anestesi termasuk ventilasi tidak efektif karena selang endotrakeal ditempatkan di fistula, dilatasi lambung, komorbid penyakit paru-paru yang sudah ada dari aspirasi sebelumnya dan / atau sindrom gangguan pernapasan prematuritas, dan adanya anomali yang terkait, terutama jantung. Manajemen anestesi berfokus pada ventilasi paruparu tanpa ventilasi fistula. Teknik ini meliputi intubasi trakea dan menghindari pelumpuh otot dan ventilasi positif yang berlebihan sampai fistel terkoreksi.

Pada fistula trakeoesophagus, fusi yang inkomplit dari tangkai trakeoesophagus menimbulkan defek pada septum trakeoesophagus dan kegagalan septum trakeoesophagus untuk membagi foregut menjadi esophagus dan trakea sehingga terjadilah fistula trakeoesophagus. Proses pemisahan ini dimulai dari bagian bawah karina kemudian berlanjut kearah atas. Dalam 26 hari kehamilan, trakea dan esophagus seharusnya telah terpisah secara total hingga setinggi laring. Rujukan yang paling sering digunakan untuk klasifikasi fistula trakeoesophagus dibedakan menjadi tipe I hingga II, tipe IIIA, IIIB dan IIIC. Tipe I atresia esophagus murni dengan tidak ada hubungan sama sekali dengan trachea terjadi sebanyak $8 \%$ dari kasus, Tipe II dikenal dengan tipe " $\mathrm{H}$ " terjadi 4\% kasus.

Tipe IIIA yaitu atresia esophagus dan fistula yang berhubungan dengan proksimal esophagus dengan trachea, terjadi hanya $1 \%$, tipe IIIB adalah atresia esophagus dan fistula distal esophagus ke trachea terjadi $75 \%-80 \%$, merupakan tipe yang paling sering terjadi. Tipe IIIC yaitu terjadi 2 fistula yang terjadi pada proksimal dan distal esophagus pada trachea, terjadi $2 \%$ $\operatorname{kasus}^{1,2,5}$.

Pada pasien dengan fistula tracheoesophagus, pengelolaan airway dan ventilasi adalah masalah yang sangat krusial. Ventilasi yang tidak efektif dapat disebabkan karena pemasangan pipa endotrakheal (ETT) pada fistula atau diatasnya, obstruksi lumen ETT dengan timbunan mucus atau gumpalan darah, 

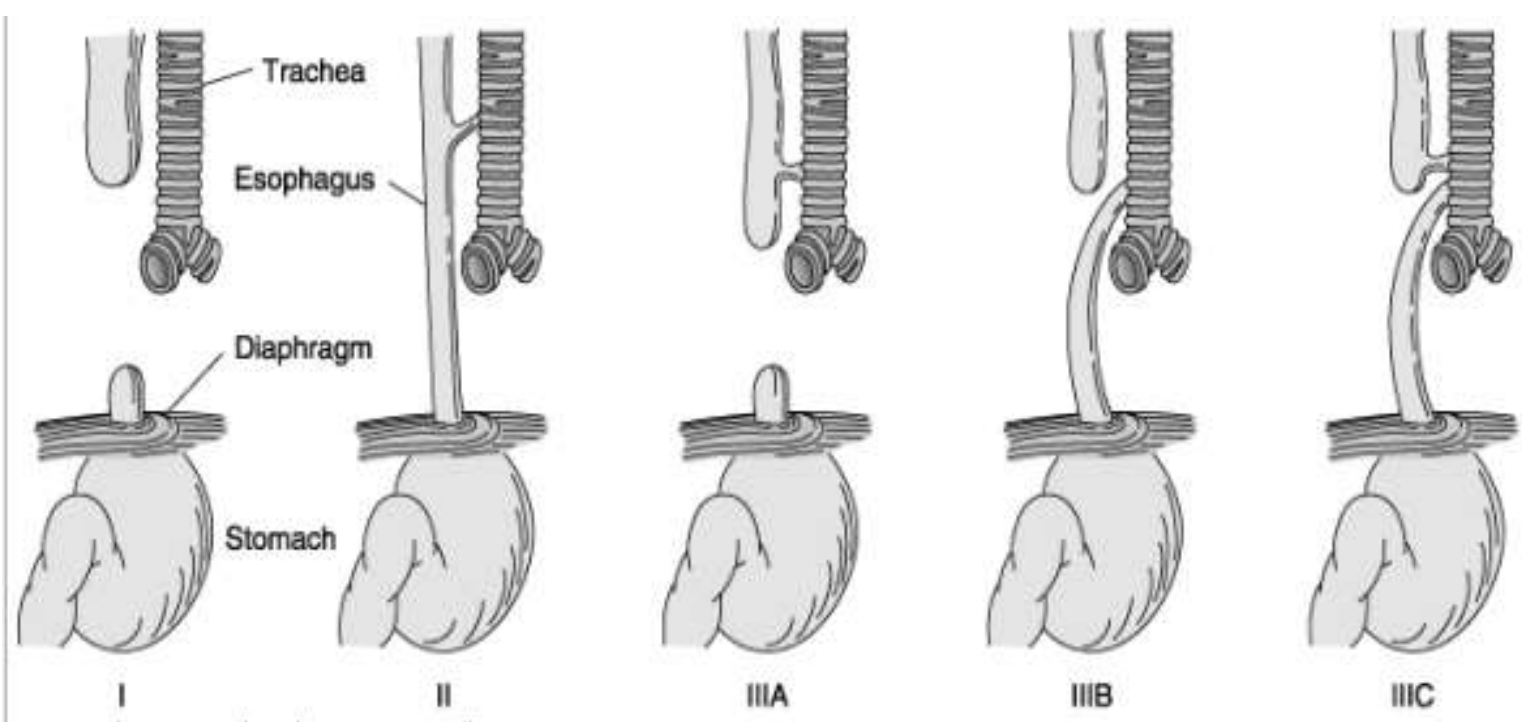

Gambar 1. Gambaran skematis tipe atresia esofagus

atau adanya kebocoran yang luas akibat penyegelan yang tidak mencukupi. Malposisi ETT juga dapat menyebabkan pelebaran lambung dan aspirasi yang kemudian muncul, distensi lambung juga dapat mengganggu ventilasi. Selain itu penyakit paru berat yang telah ada sebelumnya baik dari aspirasi isi lambung atau respirasi distress syndrome (ARDS) akibat prematuritas. Patofisiologi dari anomali yang terkait, khususnya anomali jantung. Dan yang terakhir pertimbangan prematuritas yaitu hipoglikemia, hipokalsemi, berat lahir rendah, apnea/bradikardi dan anemia ${ }^{1,3}$.

\section{MANAJEMEN PREOPERATIVE}

Penegakan diagnosis fistula trakeoesofageal ditegakkan secara klinis dan radiologis. Pada rontgen thorax, bayangan radioopak orogastic tube dapat terlihat di proksimal esophagus, sedangkan pada pemeriksaan foto polos abdomen dapat menunjukkan adanya udara dalam usus yang masuk melalui fistel. Resiko aspirasi dapat terjadi pada penggunaan kontras untuk memeriksaan fistel sehingga hanya dilakukan bila disgnosis belum jelas. Idealnya pemberian kontras dilakukan dengan bantuan bronkoskopi sehingga adanya aspirasi dapat segera diketahui. Pemeriksaan ini hanya bisa dilakukan bila bayi sudah cukup stabil dan dapat ditransfer ke ruang tindakan. ${ }^{2}$

Bronkoskopi rigid secepatnya sebelum koreksi pembedahan sangat berguna untuk mengkonfirmasi diagnosis dan posisi fistula. Hal tersebut juga memungkinkan oklusi fistula dengan balon kateter Fogarty, yang dipasang dengan bronkoskopi melalui fistula ke esophagus. Oklusi yang yang cukup pada fistula memperkecil kemungkinan distensi lambung dan memungkinkan positive pressure ventilation (PPV) intraoperatif. $^{3}$ 
Evaluasi adanya penyakit paru serta derajatnya perlu dilakukan preoperatif, khususnya untuk mencari adanya pneumonia aspirasi dan distres respirasi yang berkaitan dengan prematuritas. Pemeriksaan rongent thorak dapat menunjukkan adanya infiltrat.

Echocardiografi dapat mengetahui adanya kelainan jantung mayor yang sangat mempengaruhi survival dan akan berdampak pada pengelolaan anestesi. tujuan lain adalah untuk melihat keberadaan arcus aorta right-sided (5\%) disebelah kanan yang akan mengetahui posisi dan pendekatan pembedahan dilakukan pada sisi yang berlawanan dengan arcus aorta. Posisi left lateral decubitus untuk torakotomi kanan (torakotomi kiri untuk situs inversus). Pemeriksaan foto vertebra harus dilakukan untuk menyingkirkan abnormalitas vertebra terutama bila direncanakan untuk pengelolaan nyeri secara epidural. USG ginjal dilakukan untuk menyingkirkan abnormalitas seperti hidronefrosis. Pemeriksaan laboratorium yang dilakukan adalah darah lengkap, analisa gas darah arteri dan elektrolit serta pengambilan sampel untuk pemeriksaan golongan darah untuk cross-macth. Koreksi asidosis respiratorik dan metabolik yang terjadi,target yang akan dicapai adalah $\mathrm{pH}>7,4$ dan $\mathrm{PaCO} 2<30 \mathrm{mmHg}^{8}$

Antibiotik untuk terapi aspirasi pneumonia harus diberikan secara tepat. Ampixillin dan gentamisin dapat diberikan sebagai profilaksis pada pasien yang memiliki resiko pada jantung.

Untuk mengurangi resiko aspirasi dapat dilakukan dengan cara : menghentikan pemberian makan secara oral (NPO), bayi diposisikan semi-upright dan kantung esophagus atas lendirnya di suction terus menerus. ${ }^{2,3}$

Bila terjadi distress pernafasan dan hipoksemia muncul sebelum operasi tanpa etiologi yang jelas (sebagian besar disebabkan karena aspirasi) maka intubasi trachea merupakan pilihan yang harus segera dilakukan dan ventilasi mekanik mungkin diperlukan. Kegagalan nafas dapat diakibatkan oleh aspirasi pulmoner, ARDS, distensi lambung atau gagal jantung kongestif, EET harus hatihati dipasang untuk menghindari distensi lambung dan aspirasi. Oksigenasi yang cukup dan ventilasi serta menghindari distensi lambung. NG-tube dengan ukuran sebesar mungkin (10Fr) untuk menghindari distensi lambung, karena bila terjadi distensi akan mengakibatkan tekanan aliran udara tinggi yang akan menurunkan functional residual capacity (FRC) sehingga dapat terjadi gangguan ventilasi, oksigenasi dan meningkatkan kemungkinan aspirasi. Lakukan penghisapan pipa lambung secara kontinyu.

Berikan oksigen sungkup 100\%, nafas spontan. Jangan lakukan ventilasi positif dengan face-mask, karena akan menyebabkan distensi lambung dan memperberat kompresi paru ipsi maupun kontralateral serta kompresi mediastinum. Bila terjadi distress nafas 
atau sianosis, maka harus segera dilakukan intubasi sadar (awake intubation) dan kontrol nafas dengan relaksan dan sedasi. Usahakan tercapai saturasi oksigen $95-98 \%$.

Penempatan ETT yang cukup dengan ujung melampaui pembukaan fistula pada trakhea diatas carina, setiap perubahan posisi pasien (misalnya supinasi ke lateral) penempatan ETT harus selalu diperiksa ulang karena antara fistula, tepi ETT dan karina jaraknya pendek, hal ini dilakukan untuk menghindari distensi yang masif dan ruptur lambung dan nafas dipertahankan tetap spontan sampai fistula diligasi atau gastrostomi selesai. ${ }^{2,3,8}$

Akses vena perifer dan centralis melalui v. Jugularis interna atau subclavia. Cairan infus yang diberikan harus mengandung gula selama operasi. D10/0,2 NS diberikan intravena dengan menggunakan infus yang dikontrol dengan baik untuk menghindari terjadinya hipoglikemia. Insensible water losses diperkirakan 3-4 mL/kg/ jam dan diganti dengan cairan isotonik. Urin output normalnya $1 \mathrm{~mL} / \mathrm{kg} / \mathrm{jam}$ namun akan sulit bila bayi berat lahir normal.

Hypothermia akan meningkatkan konsumsi oksigen, temperatur lingkungan dipertahankan tepat yaitu 30 C- 40 C. Ruang operasi harus dijaga kehangatannya, begitu juga dengan cairan irigasi bedah dan darah harus dihangatkan sebelum digunakan, hal ini sangat penting karena neonatus sangat beresiko terjadinya hipotermi. Untuk mengurangi rangsangan simpatis dapat digunakan opioid (fentanyl) $)^{1,2.5}$

\section{MANAJEMEN INTRAOPERATIF}

Akses intravena harus sudah terpasang sebelum induksi, jalur kedua dapat dipasang setelah pasien teranestesi. Bila diperlukan untuk total parenteral nutrisi pada bayi dapat juga dipasang akses vena central. Arteri line untuk BGA dan monitoring hemodinamik dapat dipasang di NICU atau diruang operasi. ${ }^{3}$

Elektrokardiogram, Saturasi oksigen, end tidal $\mathrm{CO} 2$ dan rectal temperatur harus digunakan sebagai monitor. Prekordial stetoskop diletakkan pada aksila sebelah kiri untuk memonitoring suara nafas dan kemungkinan ETT tergeser selama memposisikan pasien dan pembedahan, kedua precordial stetoskop ditempatkan diatas lambung untuk mengetahui bila fistula terventilasi. Sasaran utama intubasi pada bayi adalah memberikan pertukaran oksigen yang adekuat dengan sedikit tekanan positif pada paru sehingga atelektasis dan distensi pada abdoment tidak terjadi. Tekanan positif dengan masker harus dihindari, dengan cara pertama pertahankan bayi tetap bernafas spontan sampai fistula diligasi, perdalam agent inhalasi dengan aksis pernafasan untuk meminimalisasi atelaktasis. Awake intubasi atau induksi dengan inhalasi tanpa pelumpuh otot merupakan teknik yang dianjurkan, namun harus diperhatikan kemungkinan peningkatan tekanan intracranial atau perdarahan intraventrikular pada bayi 
prematur. Intubasi dengan awake dapat diberikan $0,5-1 \mu \mathrm{g} / \mathrm{kg}$ fentanil dan 25 $50 \mu \mathrm{g} / \mathrm{kg}$ midazolam. Topikal anestesi dengan spray pada lidah, laring dan vocal cord tidak lebih dari $5 \mathrm{mg} / \mathrm{kg}$ lidocain (1,0\%). Penghisapan lendir pada kontong esophagus proksimal sebelum induksi. ${ }^{4}$

Pada kasus dimana bronkoskopi tidak dikerjakan, untuk mengkonfirmasi ETT dapat digunakan dengan cara lain, setelah induksi intubasi mainstem kanan yang disengaja dapat diikuti withdrawal perlahan ETT sehingga suara nafas terdengar disisi kiri, namun penggunaan ETT bermanset tidak dapat meminimalisasi resiko distensi lambung maupun aspirasi, untuk mengkonfirmasi posisi ETT dapat digunakan visualisasi fibroptik langsung. Sirkuit yang terpilih digunakan pada operasi ini low compression volume anesthesia breathing circuit (lingkaran sistem absorpsi vs Mapleson vs sirkuit bain). ${ }^{7}$

Monitoring selama durante operasi sangat penting selama operasi fistula tracheosophagus. Monitoring non invasif dapat berupa : temperatur,EKG, prekordial stetoskop (pada kedua hemi thorak), blood pressure, $\mathrm{SpO} 2$, urin output. Monitoring invasif dapat berupa right radial arterial line, CVC (internal jugular), differential oxymetri, End tidal $\mathrm{CO} 2$ (ET-CO2). ${ }^{4}$

\section{MANAJEMEN POSTOPERATIF}

Beberapa ahli bedah lebih menyukai bila pasien diekstubasi langsung di ruang operasi untuk meminimalisasi resiko tekanan pada sutura line. Namun sekitar $30 \%$ akan reintubasi untuk membersihkan sekresi. Tracheomalasia dapat menyebabkan obstruksi jalan nafas yang mengharuskan untuk segera dilakukan reintubasi. Beberapa anak memiliki gangguan pada paru yang berasal dari prematuritas atau aspirasi pneumoni. Pemberian narkotik untuk nyeri dapat menjadi hipoventilasi. Jika pasien tetap terintubasi setelah operasi, analgetik dengan narkotik merupakan pilihan yang tepat. Fentanil 10-20 $\mu \mathrm{g} /$ kgbb dengan muscle relaxant dapat menstabilkan hemodinamik dan memberikan efek analgesia selama periode post operasi. Analgetik dapat juga diberikan melalui caudal cateter yang dapat mencapai dermatom thorak dengan pemberian intermitten bupivacain (1-2 $\mathrm{mL}$ dari $0,125 \%$ ditambah epinefrin 1:200.000) diberikan setiap 6-8 jam atau syring pump chloroprocain $(1,5 \%)$ ditambah fentanil $(0,4 \mu \mathrm{g} / \mathrm{mL})$, untuk memastikan posisi dari kateter dapat digunakan fluoroscopy, dimana tindakan ini harus dilakukan oleh ahli regional anestesi pada anak yang berkompeten. ${ }^{2,6}$

Komplikasi awal yang terjadi setelah repair FTE dapat berupa kebocoran pada anastomosis, terjadi sekitar $15 \%$, selain itu esophagus dismotiliti dan gastroesophagus refluk disease (GERD) dapat terjadi. Tracheomalacia terjadi postoperatif dan paralisis dari pita suara telah dilaporkan. Komplikasikomplikasi lain atelectasis, tracheal 
compression, pulmonary aspirasi dan recurrent esophageal stricture. ${ }^{3}$

\section{KESIMPULAN}

Seorang bayi laki-laki, 14 hari, berat badan 2200 gr, datang ke rumah sakit dengan keluhan utama muntah setelah diberikan ASI (air susu ibu). Manajemen anestesi yang baik menggunakan "intubasi sadar" dan ventilasi yang baik merupakan pilihan pada kasus ini. Operasi berlangsung 4 jam dengan hemodinamik stabil.

\section{DAFTAR PUSTAKA}

1. Holzman.S.Robert. Kang Bhavandefl Veenu, Koka V. Babu. The Forgut and Chest In. Pediatric Anesthesia. Philadelphia, Lippicoth Willian \& Wilkins; 2008 .p. 383-9.

2. Yao.F. Funsun, Malhotra Vinod, Fontes.L. Manuel, Jacques H. Seharoun. Tracheoesophageal Fistula. In: Yao \&
Artusio's Anesthesiology Problem-Oriented Patient Management. $6^{\text {th }}$ ed. Philadelphia : Lippicot Willian \& Wilkins; 2008 .p. 105-14.

3. Miller.D Ronald, Eriksson I Lars. Fleisher. Alee, Young L William, Wiere-Krunesia Jeammine, Pediatric Anesthesia. In Miller's Anesthesia $7^{\text {th }}$ ed. San Fransisco ; Elsevier;2010 .p.2590-1.

4. Morgan Edward, Mikhail S. Maget, Murray J. Michael, Pediatric Anesthesi, In Clinical Anesthesiology, $4^{\text {th }}$ ed. San Francisco ; McGraw-Hill; 2006 .p. 941-2.

5. Bready.LL, Rasch K Deborah, Ratnamurthy S. Rajam. Tracheoesophageal Fistula. In Decision Making in Anesthesiology. $4^{\text {th }}$ ed.Texas ; Mosby Elsevier; 2007.p.368-9.

6. Lönnqvist PA, Morton NS. . Postoperative Analgesia in Infants and Children. $\mathrm{Br} \mathrm{J}$ Anaesth. 2005 Jul;95(1):59-68 .

7. Conacher ID. Anaesthesia and Tracheobronhial Stenting for Central Airway Obstruction in Adults. Br J Anaesth. 2003 ; 47(3) : 176-7.

8. Davis.N, Madden B.P, Sheth A, Crerar. Gilbert.J. Airway Management of Patients with Tracheobronhial stent. British Journal of Anaethesia. 2006 ; 96 (1) : 132-5 